\title{
Angiotensin II induces human astrocyte senescence through reactive oxygen species production
}

\author{
Gang Liu ${ }^{1,2}$, Naohisa Hosomi ${ }^{3,4}$, Hirofumi Hitomi ${ }^{1}$, Nicolas Pelisch ${ }^{4}$, Hua Fu ${ }^{4}$, Hisashi Masugata ${ }^{5}$, \\ Koji Murao $^{6}$, Masaki Ueno ${ }^{7}$, Masayasu Matsumoto ${ }^{3}$ and Akira Nishiyama ${ }^{1}$
}

Angiotensin II (Ang II)-induced astrocyte senescence may be involved in cerebral ischemic injury and age-associated neurodegenerative disease. This study was conducted to determine the roles of reactive oxygen species production in Ang II-induced cellular senescence in cultured human astrocytes. Human astrocytes were stimulated with Ang II either with or without an angiotensin type 1 receptor blocker, CV11974, or an antioxidant, tempol. Application of Ang II to human astrocytes resulted in a concentration-dependent increase in staining for dihydroethidium. Ang II ( $100 \mathrm{~nm}$ for $30 \mathrm{~min})$ increased the translocation of two cytosolic components of NADPH oxidase, p47phox and p67phox, to the cell membrane and formation of the complex of p47phox, p67phox and p22phox. Ang II concentration-dependently induced an increase in $\beta$-galactosidase staining. Pretreatment with CV11974 (100 nM) or tempol $(3 \mathrm{~mm})$ abolished Ang II-induced astrocyte $\beta$-galactosidase staining. Moreover, Ang II significantly upregulated p16 mRNA expression, which was inhibited by pretreatment with CV11974 or tempol. These findings indicate that superoxide production contributes to Ang II-induced astrocyte senescence.

Hypertension Research (2011) 34, 479-483; doi:10.1038/hr.2010.269; published online 27 January 2011

Keywords: angiotensin II; human astrocyte; NADPH oxidase; reactive oxygen species; senescence

\section{INTRODUCTION}

It has been suggested that all components of the renin-angiotensin system exist in individual tissues, thus enabling the local synthesis, release and action of angiotensin II (Ang II). ${ }^{1,2}$ The brain is a heterogeneous mixture of several cell types, including neurons and glial cells. Various components of renin-angiotensin system are expressed in glial and neural cells, suggesting a role for these cells in the central effects of Ang II. ${ }^{3}$ In particular, astrocytes are the major source of angiotensinogen in the central nervous system. ${ }^{4}$ Brain reninangiotensin system contributes to the regulation of blood pressure and water volume homeostasis through its effects on sympathetic outflow as well as vasopressin synthesis and release. ${ }^{5}$ Aged astrocytes contain elevated levels of glial fibrillary acidic and $\$ 100 \beta$ protein, ${ }^{6}$ which are involved in the neuropathology of cerebral ischemia and Alzheimer's disease. ${ }^{7}$ Recently, experimental and clinical studies have reported that cerebral ischemic injury and cognitive function can be ameliorated by inhibition of renin-angiotensin system. ${ }^{8-10}$ Additionally, brain Ang II is upregulated both in cerebral ischemia and Alzheimer's disease and can be regulated with systemic angiotensin type 1 (AT1) receptor blocker (ARB) treatment. ${ }^{9,11,12}$ Thus, Ang II-induced astrocyte senescence may be involved in the pathology of cerebral ischemic injury and age-associated neurodegenerative disease.

Superoxide and other reactive oxygen species (ROS) are recognized as important intracellular second messengers in a number of Ang II-mediated cellular processes. Cell senescence was originally described as the finite replicative lifespan of human somatic cells maintained in culture. Senescent cells enter irreversible growth arrest, exhibit a flattened and enlarged morphology and express senescence-related genes, such as p53/p21 and p16. These phenotypic changes have been implicated in aging and age-associated diseases. ${ }^{13,14}$ Recent reports have demonstrated that ROS mediate the activation of pathways that contribute to the pathogenesis of atherosclerosis (p53/p21 and p16 pathways) and initiate cellular senescence in vascular smooth muscle cells that are exposed to Ang II. ${ }^{15,16}$ In the brain, aged astrocytes exhibit a series of metabolic and morphological changes to become reactive astrocytes. These changes can be observed under a variety of conditions, including cerebral ischemia and Alzheimer's disease. ${ }^{17}$ Furthermore, ROS has roles in the pathogenesis of aging and aging-associated neurodegenerative diseases, such as Alzheimer's disease, Parkinson's disease and amyotrophic lateral sclerosis. ${ }^{18-20}$ Thus, astrocyte senescence and ROS production may

\footnotetext{
${ }^{1}$ Department of Pharmacology, Kagawa University School of Medicine, Kagawa, Japan; ${ }^{2}$ Department of Anesthesiology, First Affiliated Hospital of China Medical University, Shenyang, China; ${ }^{3}$ Department of Clinical Neuroscience and Therapeutics, Hiroshima University Graduate School of Biomedical Sciences, Hiroshima, Japan; ${ }^{4}$ Department of Cardiorenal and Cerebrovascular Medicine, Kagawa University School of Medicine, Kagawa, Japan; ${ }^{5}$ Department of Integrated Medicine, Kagawa University School of Medicine, Kagawa, Japan; ${ }^{6}$ Department of Internal Medicine, Kagawa University School of Medicine, Kagawa, Japan and ${ }^{7}$ Department of Pathology and Host Defense, Kagawa University School of Medicine, Kagawa, Japan

Correspondence: Dr N Hosomi, Department of Clinical Neuroscience and Therapeutics, Hiroshima University Graduate School of Biomedical Sciences, 1-2-3 Kasumi, Minami-Ku, Hiroshima 734-8551, Japan.

E-mail: nhosomi@hiroshima-u.ac.jp

Received 10 July 2010; revised 8 October 2010; accepted 10 October 2010; published online 27 January 2011
} 
have important roles in cerebral ischemia and in the development of ageassociated neurodegenerative diseases.

In this study, we hypothesized that Ang II has a direct effect on ROS generation through AT1 receptor-dependent activation of NADPH oxidase and that this interaction could contribute to Ang II-induced human astrocyte senescence. To test this hypothesis, we examined the effects of Ang II, ARB and an antioxidant on superoxide generation and cell senescence in cultured human astrocytes.

\section{METHODS}

\section{Reagents}

Ang II, tempol and anti- $\beta$ actin antibody were purchased from Sigma Chemical (St Louis, MO, USA). Dihydroethidium was obtained from Molecular Probes (Eugene, OR, USA). Anti-p47phox, -p67phox and -p22phox antibodies were purchased from Santa Cruz Biotechnology (Santa Cruz, CA, USA). CV11974 and ARB, were provided by Takeda Chemical Industries (Osaka, Japan).

\section{Cell culture}

All experimental procedures were performed according to the guidelines for the care and use of animals established by Kagawa University School of Medicine. Primary human brain astrocytes (ACBRI 371) were purchased from the Applied Cell Biology Research Institute (Kirkland, WA, USA) and were maintained in CS-C Medium Kits (Cell Systems, Kirkland, WA, USA). Characteristics of this primary human brain astrocytes were described previously. ${ }^{21,22}$ After stimulation, protein or mRNA was extracted as described previously. ${ }^{9,23}$ The protein concentration was determined using the Bradford assay kit (Bio-Rad Laboratories, Hercules, CA, USA).

Astrocytes were stimulated for 1 or 3 day(s) with Ang II at an appropriate final concentration, beginning on day 1 . For the 7-days stimulation experiments, astrocytes were stimulated with Ang II on day 1, and medium was changed on day 3 with the same Ang II final concentration.

\section{Senescence-associated $\beta$-galactosidase staining}

Astrocytes were washed with phosphate-buffered solution and fixed in $4 \%$ paraformaldehyde in phosphate-buffered solution for $30 \mathrm{~min}$. This was followed by three washes with phosphate-buffered solution. The degree of senescence in astrocyte cultures was evaluated using the senescence-associated $\beta$-galactosidase (SA $\beta$-gal) staining kit (Sigma Chemical) according to the manufacturer's instructions. Senescent astrocytes (stained blue) were observed with a microscope and digitally photographed.

\section{Dihydroethidium staining}

The oxidative fluorescence of dihydroethidium was used to evaluate intracellular $\mathrm{O}_{2}{ }^{-}$levels as described previously. ${ }^{24}$ Briefly, human astrocytes were plated in a glass-bottom dish (Matsunami Glass Ind., Kishiwada, Japan) and allowed to adhere for at least $18 \mathrm{~h}$. At the appropriate time after stimulation, dihydroethidium $(5 \mu \mathrm{M})$ was added to the medium, and the incubation was continued for $15 \mathrm{~min}$. Cells were then washed with phosphate-buffered solution, and images were obtained using a laser scanning confocal microscope system (Bio-Rad Laboratories). The average of fluorescence intensity values from 20 to 30 cells, taken from six different examinations, were calculated using ImageJ from the National Institutes of Health.

\section{Real-time reverse transcriptase PCR}

mRNA expression levels of p16 were analyzed by real-time reverse transcriptase PCR. All data were normalized against the expression of the glyceraldehyde-3phosphate dehydrogenase gene. The sense and antisense sequences for p16 were

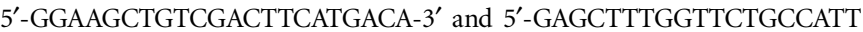
TG-3', respectively.

\section{NADPH oxidase complex formation}

NADPH oxidase complex formation was assessed by immunoprecipitation/ western blotting as previously described. ${ }^{25}$ Quiescent astrocytes treated with Ang II for $30 \mathrm{~min}$ were lysed in cold lysis buffer consisting of $20 \mathrm{~mm}$ Tris- $\mathrm{HCl}$,
pH 7.4, $140 \mathrm{~mm} \mathrm{NaCl}, 1 \%$ Triton-X, $10 \%$ glycerol, $1 \mathrm{~mm} \beta$-glycerophosphate, $1 \mathrm{~mm}$ sodium orthovanadate and complete protease inhibitor tablet (Roche, Mannheim, Germany; 1 tablet per $25 \mathrm{ml}$ buffer). The homogenates were then subjected to sonication for $10 \mathrm{~s}$ on ice (repeated three times), followed by centrifugation for $30 \mathrm{~min}$ at $12000 \mathrm{~g}$ to remove cellular debris. The same amount of protein $(100 \mu \mathrm{g})$ was incubated with $4 \mu \mathrm{g}$ of polyclonal anti-p22phox overnight at $4{ }^{\circ} \mathrm{C}$. The resulting immune complexes were precipitated by incubation with protein-A/G sepharose for a further $2 \mathrm{~h}$ at $4^{\circ} \mathrm{C}$. After they had been washed twice, the pellets were resuspended in $2 \times$ Laemmli sample buffer, boiled for $5 \mathrm{~min}$, and subjected to SDS-polyacrylamide gel electrophoresis following semidry transfer to polyvinylidene difluoride membranes, the membranes were probed with p47phox, p67phox and p22phox antibodies overnight at $4{ }^{\circ} \mathrm{C}$, before being incubated for $1 \mathrm{~h}$ with a secondary antibody (horseradish peroxidase-conjugated anti-rabbit IgG, 1:2000). Immunoreactive bands were visualized using enhanced chemiluminescence (ECL; Amersham Pharmacia Biotech Inc., Piscataway, NJ, USA) and quantified by densitometry in the linear range of film exposure using LAS_-1000 plus (FUJIFILM Co., Tokyo, Japan).

\section{Statistical analyses}

The values are presented as mean \pm s.d. One-way analysis of variance was used to determine significant differences among groups. When the overall analysis of variance $P$-value was $<0.05$, Bonferroni's correction for multiple comparisons was used to assess individual group differences. $P<0.05$ was considered statistically significant.

\section{RESULTS}

\section{Effect of Ang II on astrocyte senescence}

Senescence characteristics in astrocyte cultures were evaluated using SA $\beta$-gal staining. Figure 1a shows the time course of Ang II-induced increases in SA $\beta$-gal-positive cells $(n=12$ for each). After treatment with Ang II ( $100 \mathrm{~nm})$ for 3 or 7 days, the number of SA $\beta$-gal-positive cells was significantly higher than in the control group $(P<0.01)$. Figure $1 \mathrm{~b}$ shows the concentration-dependent effects of Ang II ( 3 days treatment) on the number of SA $\beta$-gal-positive cells ( $n=12$ for each). Treatment with either 10 or $100 \mathrm{~nm}$ Ang II significantly increased the number of SA $\beta$-gal-positive cells.

\section{Effect of Ang II on $\mathrm{O}_{2}^{-}$production}

To determine whether Ang II stimulates ROS production in human astrocytes, intracellular $\mathrm{O}_{2}{ }^{-}$level was evaluated with dihydroethidium staining. Figure 2a shows the time course of Ang II-induced increases in dihydroethidium staining ( $n=6$ for each). Ang II-induced ( $100 \mathrm{~nm}$ ) increases in dihydroethidium staining peaked at $30 \mathrm{~min}$. Figure $2 \mathrm{~b}$ shows the concentration-dependent effects of Ang II $(30 \mathrm{~min})$ on dihydroethidium staining ( $n=6$ for each). Moreover, pretreatment with CV11974 (100 nM) for $3 \mathrm{~h}$ significantly attenuated the Ang II-induced $(1000 \mathrm{~nm})$ increases in dihydroethidium staining. Representative results of dihydroethidium staining are shown in Figure $2 \mathrm{~b}$.

\section{Effect of Ang II on NADPH oxidase complex formation}

Activation of NADPH oxidase requires translocation of its cytosolic components, p47phox and p67phox, to the cell membrane and formation of a complex between p47phox, p67phox and p22phox. Therefore, we examined the effects of Ang II on the complex formation of p47phox, p67phox and p22phox in astrocytes by immunoprecipitation/western blotting analysis. As shown in Figure 3, Ang II induced complex formation of NADPH oxidase in a concentration-dependent manner. Additionally, pretreatment with CV11974 (100 nM) significantly attenuated Ang II-induced ( $1000 \mathrm{nM})$ complex formation ( $n=4$ for each). As a control for the immunoprecipitations, the amounts of p47phox, p67phox and p22phox precipitated in each group were determined through direct immunoblotting; the levels of these components in each group were essentially constant (data not shown). 


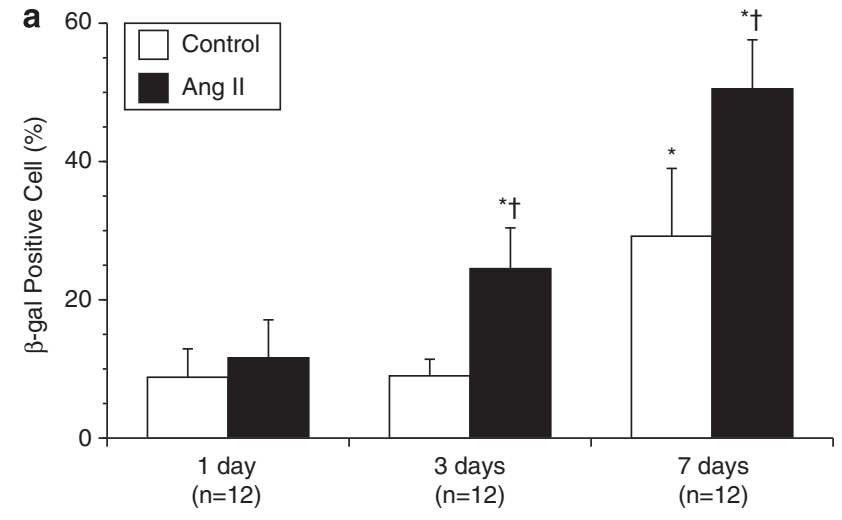

Duration of Stimulation

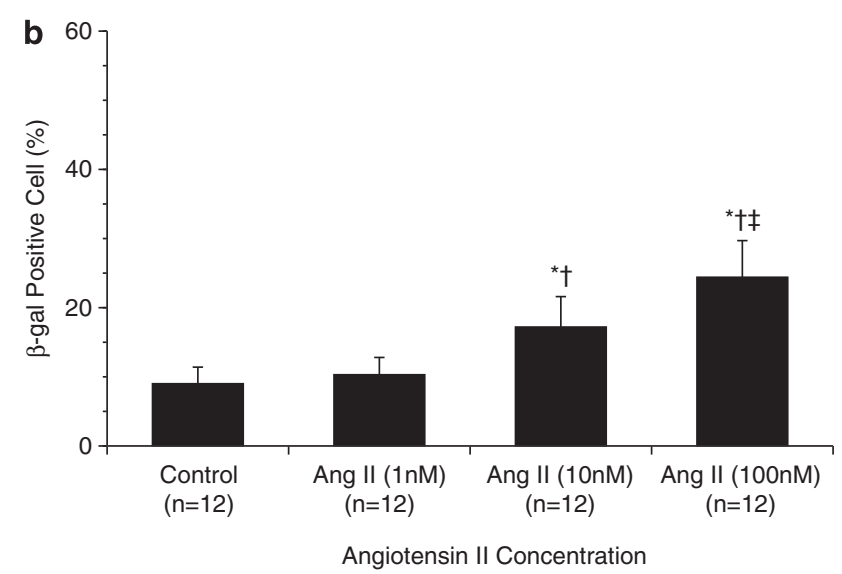

Figure 1 Effect of Ang II on cellular senescence in human astrocytes. $\beta$-galactosidase staining was used to evaluate cellular senescence. (a) Time course of Ang II (100 nm)-induced cellular senescence. ${ }^{*} P<0.05$ vs. 1 day, $\dagger P<0.05$ vs. control. (b) Concentration-dependent effects of Ang II (3 days) on cellular senescence. ${ }^{*} P<0.05$ vs. control, ${ }^{\dagger} P<0.05$ vs. Ang II (1 nM), $\ddagger P<0.05$ vs. Ang II (10 nm).

\section{Effects of CV11974 and tempol on Ang II-induced astrocyte senescence}

To investigate the role of AT1 receptor and $\mathrm{O}_{2}{ }^{-}$production in Ang IIinduced astrocyte senescence, the effects of CV11974 (an AT1 receptor blocker) and tempol (a superoxide dismutase mimetic) on the number of SA $\beta$-gal-positive cells were examined ( $n=6$ for each). Before incubation with Ang II (100 nM), astrocytes were pretreated with either CV11974 (100 $\mathrm{nm})$ for $3 \mathrm{~h}$ or tempol $(3 \mathrm{~mm})$ for $30 \mathrm{~min}$. As shown in Figure 4b, CV11974 significantly inhibited the Ang IIinduced increase in the number of SA $\beta$-gal-positive cells $(P<0.01)$. In addition, the Ang II-induced increase in SA $\beta$-gal-positive cells was attenuated after preincubation with tempol $(P<0.01)$. Representative results of the $\beta$-galactosidase staining are shown in Figure 4 . These results suggest that Ang II induces astrocyte senescence through an $\mathrm{O}_{2}{ }^{-}$production-dependent pathway that involves the AT1 receptor.

\section{Effect of Ang II on p16 mRNA expression}

To further investigate the mechanism of Ang II-induced astrocyte senescence, the expression of p16 mRNA was examined. As shown in Figure 5, after 3-days treatment with Ang II (100 nM), p16 mRNA expression was significantly higher than in the control group ( $n=6$ for each, $P<0.05)$. Moreover, CV11974 (100 nM) and tempol $(3 \mathrm{~mm})$ significantly blocked Ang II-induced increases in p16 mRNA
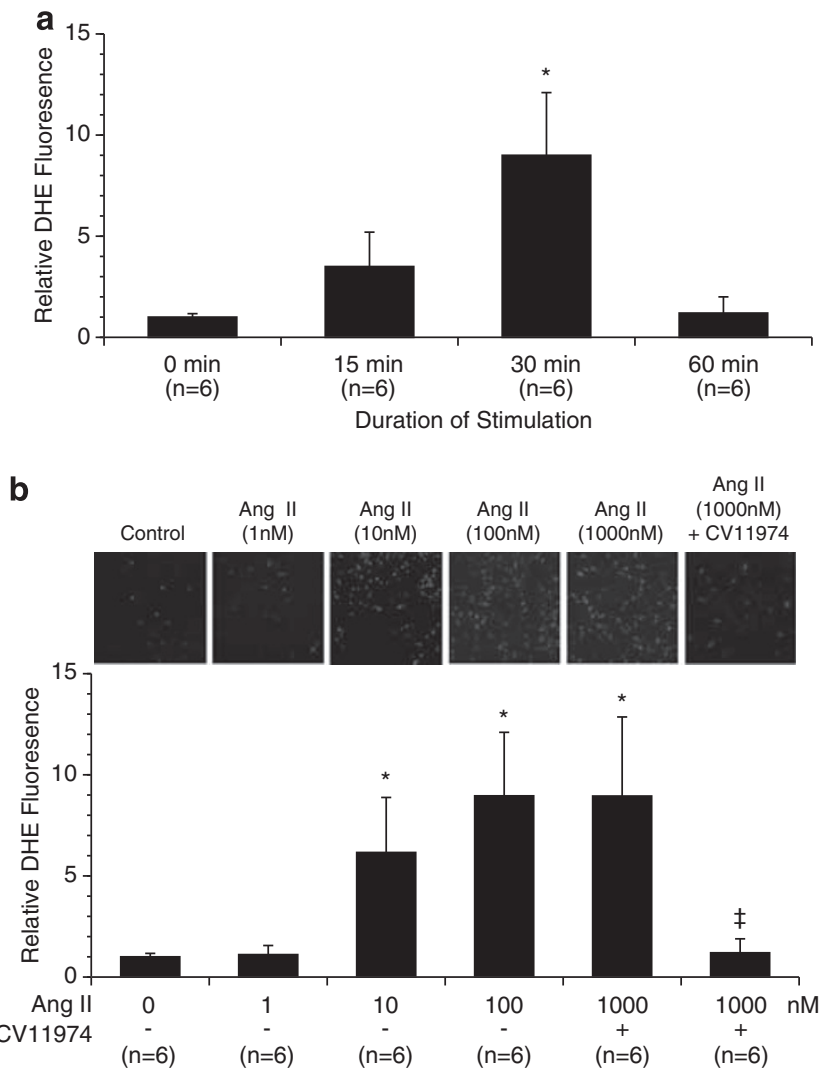

Figure 2 Effect of Ang II on superoxide production in human astrocytes. Dihydroethidium (DHE) staining was used to evaluate superoxide anion level. (a) Time course of Ang II (100 nm)-induced superoxide production. ${ }^{*} P<0.05$ vs. 0 min. (b) Concentration-dependent effects of Ang II (30 min) on superoxide production, as well as the effect of CV11974 (100 nm) on Ang II $(1000 \mathrm{~nm})$-induced superoxide production. ${ }^{*} P<0.05$ vs. control, $\ddagger P<0.01$ vs. Ang II $(1000 \mathrm{~nm})$. Original magnification, $\times 100$. A full color version of this figure is available at the Hypertension Research journal online.

expression. This suggests that p16 may be involved in Ang II-induced astrocyte senescence.

\section{DISCUSSION}

This study shows that Ang II directly induced superoxide production in human astrocytes and that this mechanism contributed to Ang IIinduced astrocyte senescence. In addition, these effects of Ang II were inhibited by pretreatment with the ARB CV11974. This suggests that the AT1 receptor may have a role in mediating these effects of Ang II.

A signaling mechanism for Ang II that involves superoxide and other ROS has been identified in peripheral tissues. Ang II stimulates ROS generation and activates molecules associated with redox regulation in the vasculature, ${ }^{26}$ heart ${ }^{27}$ and kidney. ${ }^{2}$ In addition, superoxide mediates the actions of Ang II in the central nervous system, including in its regulation of blood pressure, heart rate and drinking behavior. ${ }^{28}$ Moreover, NADPH oxidase inhibition attenuates the neuronal chronotropic actions of Ang II. ${ }^{29}$ To the best of our knowledge, this study is the first to demonstrate that Ang II stimulates AT1-dependent dihydroethidium fluorescence in human astrocytes. Furthermore, the Ang II-induced production of superoxide was abolished by pretreatment with ARB.

NADPH oxidase is composed of membrane-associated components (gp91phox and p22phox) and cytosolic regulatory subunits (p40phox, p47phox, p67phox and Rac). ${ }^{30}$ Activation of NADPH oxidase requires 
a

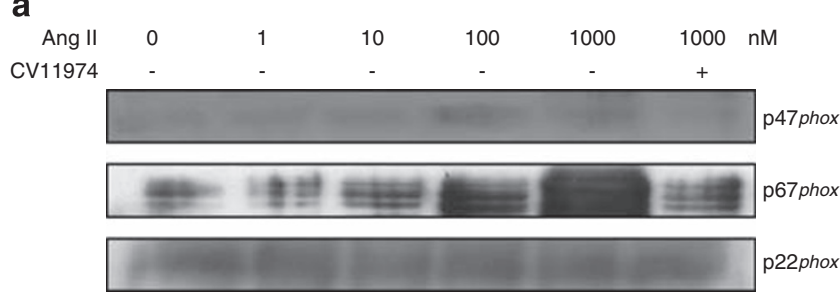

b

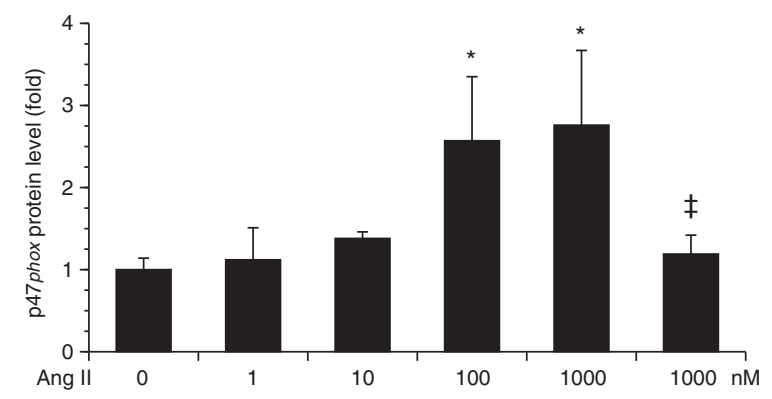

CV11974

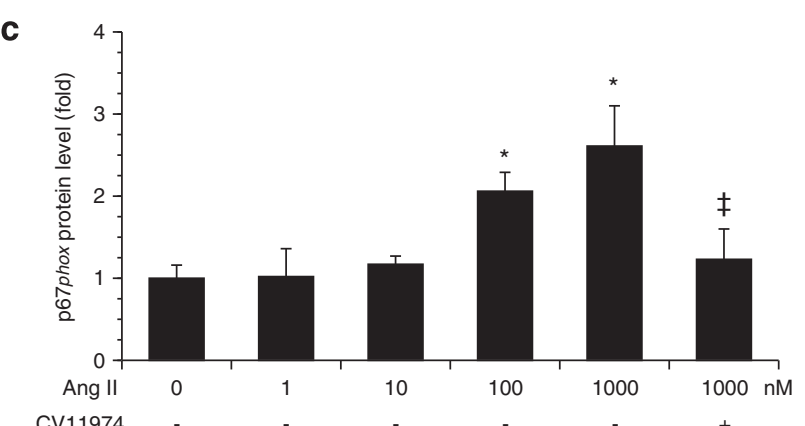

Figure 3 Ang II concentration dependence of NADPH p47phox, p67phox and p22phox complex formation, as well as the effect of CV11974 on Ang II (1000 nm, $30 \mathrm{~min}$ )-induced p47phox, p67phox and p22phox complex formation in human astrocytes. (a) Original pictures of immunoblottings with p47phox, p67phox, and p22phox. (b) Relative changes of integrated density in p47phox protein. (c) Relative changes of integrated density in p67phox protein. ${ }^{*} P<0.05$ vs. Ang II $(0 \mathrm{~nm}), \stackrel{\ddagger}{\ddagger}<0.01$ vs. Ang II (1000 nm).

translocation of the cytosolic components to the cell membrane. Our study shows that Ang II directly induces both the translocation of p47phox and p67phox to the astrocyte membrane and the binding of p22phox to them. Moreover, the time courses of Ang II-induced superoxide production and membranous translocation of p47phox and p67phox were similar. Pretreatment with ARB abolished not only superoxide production but also the translocation of p47phox and p67phox to the membrane. Thus, these data are consistent with the concept that membranous translocation of p47phox and p67phox is involved, at least in part, in the overall elevation in superoxide production in human astrocytes. This study also indicated the potential contribution of the AT1 receptor to these effects of Ang II in human astrocytes.

The tumor suppressor proteins $\mathrm{p} 53$ and $\mathrm{pRb}$ regulate two pathways that contribute to the establishment and maintenance of cellular senescence. ${ }^{14}$ Both proteins are transcriptional regulators, and they are crucially involved in signaling pathways that are responsible for cell cycle regulation, DNA repair and cell death. ${ }^{31}$ Recent studies have indicated that Ang II induces cell senescence through a p53/p21dependent pathway in vascular smooth muscle cells and endothelial cells. ${ }^{15,32}$ Moreover, Min et al ${ }^{16}$ have also reported that $\mathrm{p} 16$ is involved in Ang II-induced vascular smooth muscle cell senescence. p16 is a
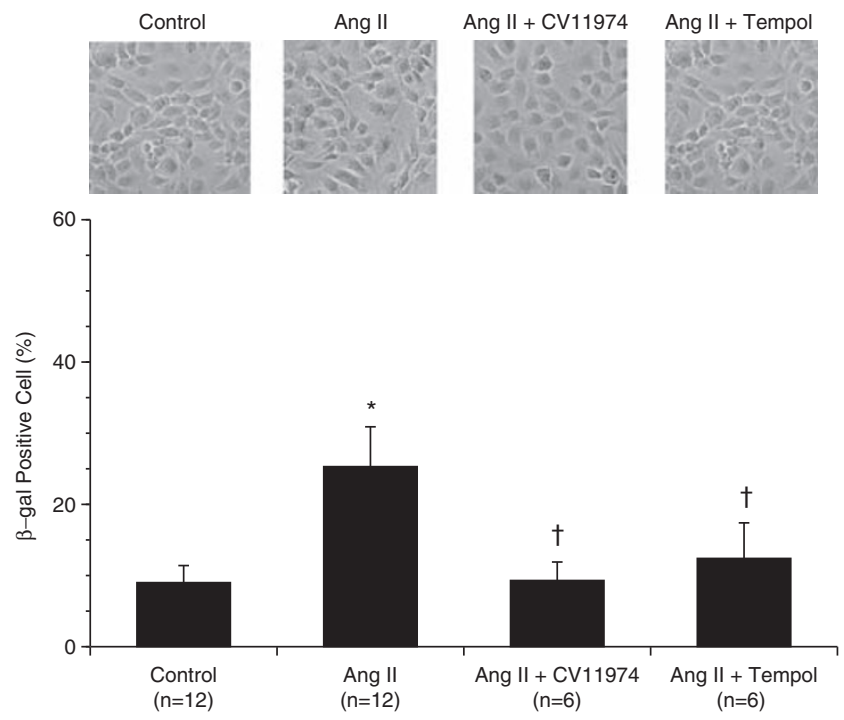

Figure 4 Effects of CV11974 and tempol on Ang II-induced human astrocyte senescence. The $\beta$-galactosidase staining was used to evaluate cellular senescence. Before stimulation with Ang II (100 nm, 3 days), CV11974 (100 nm) and tempol ( $3 \mathrm{~mm})$ were preincubated for $3 \mathrm{~h}$ and 30 min, respectively. ${ }^{*} P<0.05$ vs. control, ${ }^{\dagger} P<0.01$ vs. Ang II. Original magnification, $\times 200$. A full color version of this figure is available at the Hypertension Research journal online.

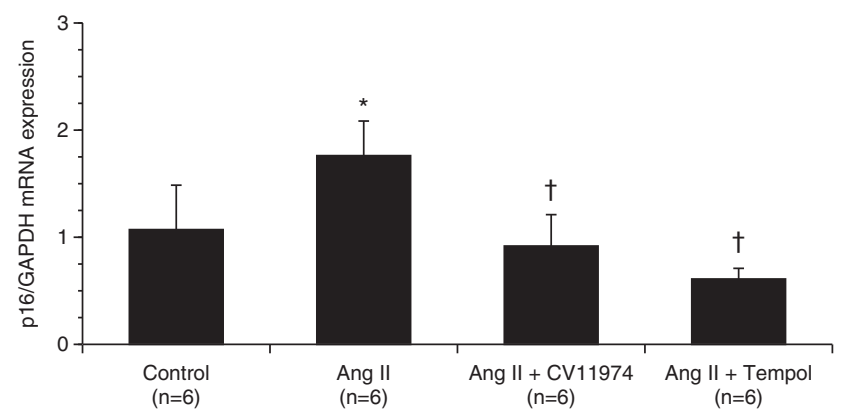

Figure 5 Effects of CV11974 and tempol on Ang II (100 nm, 3 days)induced p16 mRNA expression in human astrocytes. All data were normalized against GAPDH mRNA and the ratio to the control is shown. ${ }^{*} P<0.05$ vs. control, ${ }^{\dagger} P<0.01$ vs. Ang II $(100 \mathrm{~nm})$.

positive regulator of $\mathrm{pRb}$ that is induced by a variety of stress stimuli, including Ang II. ${ }^{16,33}$ Furthermore, ROS mediate the activation of p53/p21 and p16 pathways as well as cellular senescence induced by Ang II. ${ }^{15,16}$ In this study, we found that Ang II upregulated p16 mRNA expression but not $\mathrm{p} 53$ or p21 expression (data not shown). Pretreatment with ARB or tempol attenuated Ang II-induced upregulation of p16. This suggests that p16 might be involved in Ang II-induced human astrocyte senescence.

It will be important to explain how astrocyte senescence, which we observed under Ang II stimulation, is involved in pathological conditions. Several reports have evaluated the functional changes that occur in senescent astrocytes. Similar to activated astrocytes, senescent astrocytes lose their neuroprotective function and show increased expression of glial fibrillary acidic protein and $S 100 \beta .{ }^{34}$ However, to our knowledge, no study has evaluated SA $\beta$-gal expression in astrocytes in vivo. As neurodegenerative diseases progress slowly, Ang II-induced astrocyte senescence may not be the only mechanism underlying neurodegenerative disease. In our experimental cerebral ischemia rat model, rat brain Ang II content increases following 
reperfusion, but at around $50 \mathrm{fmol} \mathrm{g}^{-1}$ tissue, it is still approximately $1 / 2000$ of the in vitro level $\left(100 \mathrm{nM}=100 \mathrm{pmol} \mathrm{ml}^{-1}\right)$ used in this study. ${ }^{9,12}$ Even in plasma, Ang II content (around $150 \mathrm{pM}=$ $150 \mathrm{fmol} \mathrm{ml}^{-1}$ ) in those rats is also around $1 / 600$ of the in vitro condition used in this study. ${ }^{12}$ Therefore, we believe it is not easy to be similar Ang II stimulation conditions under in vivo cerebral ischemia to in vitro Ang II stimulation made in this study. Additionally, there may also exist systemic counter-action mechanisms against Ang II-stimulated astrocyte senescence. Our results suggest that systemic superoxide dismutase or NADPH oxidase inhibitors can assist these counter-action mechanisms against Ang II-stimulated astrocyte senescence.

Ischemic or hemorrhagic strokes can have a number of neurological consequences, including cognitive impairment and the eventual development of dementia. ${ }^{35}$ In addition to its effect on cerebral ischemia, treatment with ARB may improve cognitive function and dementia. The Study on Cognition and Prognosis in the Elderly has reported that antihypertensive therapy with the ARB candesartan prevents the decline of cognitive function and reduces the incidence of dementia in elderly nondemented patients. ${ }^{8}$ Recent reports have also demonstrated that valsartan improves Alzheimer's disease through mechanisms that affect $\beta$-amyloid protein neuropathology, but are independent of blood pressure-lowering activity. ${ }^{36}$ Thus, Ang II-induced astrocyte senescence may be involved in cerebral ischemic injury and age-associated neurodegenerative diseases.

In summary, this study demonstrates that Ang II directly induces astrocyte senescence through a superoxide production-dependent mechanism. Ang II-induced superoxide production may result, at least in part, from membranous translocation of p47phox and p67phox. Our data also indicate a role for the AT1 receptor in the Ang II-mediated production of superoxide anions and astrocyte senescence. These findings provide novel insights into the mechanisms responsible for Ang IIinduced ROS production during the progression of cerebral ischemic injury and age-associated neurodegenerative diseases.

\section{CONFLICT OF INTEREST}

The authors declare no conflict of interest.

\section{ACKNOWLEDGEMENTS}

We would like to show our gratitude to Ms Shiho Kobayashi for her technical assistance. CV11974 was kindly provided by Takeda Pharmaceutical Company Ltd (Osaka, Japan). This study was supported with Grants in Aid for Scientific Research from the Ministry of Education, Culture, Sports \& Technology of Japan (\#18590945) to Dr Naohisa Hosomi from April 2006 to March 2009.

1 McKinley MJ, Albiston AL, Allen AM, Mathai ML, May CN, McAllen RM, Oldfield BJ, Mendelsohn FA, Chai SY. The brain renin-angiotensin system: location and physiological roles. Int J Biochem Cell Biol 2003; 35: 901-918.

2 Kobori H, Nangaku M, Navar LG, Nishiyama A. The intrarenal renin-angiotensin system: from physiology to the pathobiology of hypertension and kidney disease. Pharmacol Rev 2007; 59: 251-287.

3 Saavedra JM. Brain angiotensin II: new developments, unanswered questions and therapeutic opportunities. Cell Mol Neurobiol 2005; 25: 485-512.

4 Stornetta RL, Hawelu-Johnson CL, Guyenet PG, Lynch KR. Astrocytes synthesize angiotensinogen in brain. Science 1988; 242: 1444-1446.

5 Phillips MI, Sumners C. Angiotensin II in central nervous system physiology. Regul Pept 1998; 78: 1-11.

6 Griffin WS, Sheng JG, Mrak RE. Senescence-accelerated overexpression of S100beta in brain of SAMP6 mice. Neurobiol Aging 1998; 19: 71-76.

7 Griffin WS. Inflammation and neurodegenerative diseases. Am J Clin Nutr 2006; 83 470S-474S.

8 Lithell H, Hansson L, Skoog I, Elmfeldt D, Hofman A, Olofsson B, Trenkwalder P, Zanchetti A. The Study on Cognition and Prognosis in the Elderly (SCOPE): principal results of a randomized double-blind intervention trial. J Hypertens 2003; 21: 875-886.
9 Hosomi N, Nishiyama A, Ban CR, Naya T, Takahashi T, Kohno M, Koziol JA. Angiotensin type 1 receptor blockage improves ischemic injury following transient focal cerebral ischemia. Neuroscience 2005; 134: 225-231.

10 Mogi M, Li JM, Iwanami J, Min LJ, Tsukuda K, Iwai M, Horiuchi M. Angiotensin II type2 receptor stimulation prevents neural damage by transcriptional activation of methyl methanesulfonate sensitive 2. Hypertension 2006; 48: 141-148.

11 Savaskan E, Hock C, Olivieri G, Bruttel S, Rosenberg C, Hulette C, Muller-Spahn F. Cortical alterations of angiotensin converting enzyme, angiotensin II and AT1 receptor in Alzheimer's dementia. Neurobiol Aging 2001; 22: 541-546.

12 Pelisch $\mathrm{N}$, Hosomi N, Ueno M, Masugata H, Murao K, Hitomi H, Nakano D, Kobori $\mathrm{H}$, Nishiyama A, Kohno M. Systemic candesartan reduces brain angiotensin II via downregulation of brain renin-angiotensin system. Hypertens Res 2010; 33: 161-164.

13 Minamino T, Komuro I. Vascular cell senescence: contribution to atherosclerosis. Circ Res 2007; 100: 15-26.

14 Campisi J. Senescent cells, tumor suppression, and organismal aging: good citizens, bad neighbors. Cell 2005; 120: 513-522.

15 Kunieda T, Minamino T, Nishi J, Tateno K, Oyama T, Katsuno T, Miyauchi H, Orimo M, Okada S, Takamura M, Nagai T, Kaneko S, Komuro I. Angiotensin II induces premature senescence of vascular smooth muscle cells and accelerates the development of atherosclerosis via a p21-dependent pathway. Circulation 2006; 114: 953-960.

16 Min LJ, Mogi M, Iwanami J, Li JM, Sakata A, Fujita T, Tsukuda K, Iwai M, Horiuchi M. Cross-talk between aldosterone and angiotensin II in vascular smooth muscle cell senescence. Cardiovasc Res 2007; 76: 506-516.

17 Cotrina ML, Nedergaard M. Astrocytes in the aging brain. J Neurosci Res 2002; 67: 1-10.

18 Smith MA, Richey Harris PL, Sayre LM, Beckman JS, Perry G. Widespread peroxynitrite-mediated damage in Alzheimer's disease. J Neurosci 1997; 17: 2653-2657.

19 Gotz ME, Freyberger A, Riederer P. Oxidative stress: a role in the pathogenesis of Parkinson's disease. J Neural Transm Supp/ 1990; 29: 241-249.

20 Deng HX, Hentati A, Tainer JA, Iqbal Z, Cayabyab A, Hung WY, Getzoff ED, Hu P, Herzfeldt B, Roos RP, Warner C, Deng G, Soriano E, Smyth C, Parge HE, Ahmed A, Roses AD, Hallewell RA, Pericak-Vance MA, Siddique T. Amyotrophic lateral sclerosis and structural defects in Cu,Zn superoxide dismutase. Science 1993; 261: 1047-1051.

21 Payner T, Leaver HA, Knapp B, Whittle IR, Trifan OC, Miller S, Rizzo MT. Microsomal prostaglandin $\mathrm{E}$ synthase-1 regulates human glioma cell growth via prostaglandin E(2)-dependent activation of type II protein kinase A. Mol Cancer Ther 2006; 5 : 1817-1826.

22 Choi YK, Kim JH, Kim WJ, Lee HY, Park JA, Lee SW, Yoon DK, Kim HH, Chung H, Yu YS, Kim KW. AKAP12 regulates human blood-retinal barrier formation by downregulation of hypoxia-inducible factor-1alpha. J Neurosci 2007; 27: 4472-4481.

23 Nishiyama A, Yao L, Fan Y, Kyaw M, Kataoka N, Hashimoto K, Nagai Y, Nakamura E, Yoshizumi M, Shokoji T, Kimura S, Kiyomoto H, Tsujioka K, Kohno M, Tamaki T, Kajiya $\mathrm{F}$, Abe Y. Involvement of aldosterone and mineralocorticoid receptors in rat mesangial cell proliferation and deformability. Hypertension 2005; 45: 710-716.

24 Miyata K, Rahman M, Shokoji T, Nagai Y, Zhang GX, Sun GP, Kimura S, Yukimura T, Kiyomoto $\mathrm{H}$, Kohno M, Abe $\mathrm{Y}$, Nishiyama A. Aldosterone stimulates reactive oxygen species production through activation of NADPH oxidase in rat mesangial cells. J Am Soc Nephrol 2005; 16: 2906-2912.

25 Kimura S, Zhang GX, Nishiyama A, Shokoji T, Yao L, Fan YY, Rahman M, Suzuki T, Maeta $\mathrm{H}$, Abe $\mathrm{Y}$. Role of $\mathrm{NAD}(\mathrm{P}) \mathrm{H}$ oxidase- and mitochondria-derived reactive oxygen species in cardioprotection of ischemic reperfusion injury by angiotensin II. Hypertension 2005; 45: 860-866.

26 Griendling KK, Minieri CA, Ollerenshaw JD, Alexander RW. Angiotensin II stimulates NADH and NADPH oxidase activity in cultured vascular smooth muscle cells. Circ Res 1994; 74: 1141-1148.

27 Nakamura K, Fushimi K, Kouchi H, Mihara K, Miyazaki M, Ohe T, Namba M. Inhibitory effects of antioxidants on neonatal rat cardiac myocyte hypertrophy induced by tumor necrosis factor-alpha and angiotensin II. Circulation 1998; 98: 794-799.

28 Zimmerman MC, Lazartigues E, Lang JA, Sinnayah P, Ahmad IM, Spitz DR, Davisson RL. Superoxide mediates the actions of angiotensin II in the central nervous system. Circ Res 2002; 91: 1038-1045.

29 Zimmerman MC, Sharma RV, Davisson RL. Superoxide mediates angiotensin II-induced influx of extracellular calcium in neural cells. Hypertension 2005; 45: 717-723.

30 Abramov AY, Jacobson J, Wientjes F, Hothersall J, Canevari L, Duchen MR. Expression and modulation of an NADPH oxidase in mammalian astrocytes. J Neurosci 2005; 25: 9176-9184.

31 Sherr CJ, McCormick F. The RB and p53 pathways in cancer. Cancer Cell 2002; 2 : 103-112.

32 Scalera F, Martens-Lobenhoffer J, Bukowska A, Lendeckel U, Tager M, Bode-Boger SM. Effect of telmisartan on nitric oxide-asymmetrical dimethylarginine system: role of angiotensin II type 1 receptor gamma and peroxisome proliferator activated receptor gamma signaling during endothelial aging. Hypertension 2008; 51: 696-703.

33 Westhoff JH, Hilgers KF, Steinbach MP, Hartner A, Klanke B, Amann K, Melk A. Hypertension induces somatic cellular senescence in rats and humans by induction of cell cycle inhibitor p16INK4a. Hypertension 2008; 52: 123-129.

34 Pertusa M, Garcia-Matas S, Rodriguez-Farre E, Sanfeliu C, Cristofol R. Astrocytes aged in vitro show a decreased neuroprotective capacity. J Neurochem 2007; 101: 794-805.

35 Trenkwalder P. Potential for antihypertensive treatment with an AT(1)-receptor blocker to reduce dementia in the elderly. J Hum Hypertens 2002; 16 (Suppl 3): S71-S75.

36 Wang J, Ho L, Chen L, Zhao Z, Zhao W, Qian X, Humala N, Seror I, Bartholomew S, Rosendorff C, Pasinetti GM. Valsartan lowers brain beta-amyloid protein levels and improves spatial learning in a mouse model of Alzheimer disease. J Clin Invest 2007; 117: 3393-3402. 